Journal of Current and Advance Medical Research

July 2017, Vol. 4, No. 2, pp. 40-43

http://www.banglajol.info/index.php/JCAMR

ISSN (Print) 2313-447X

ISSN (Online) 2413-323X

DOI: http://dx.doi.org/10.3329/jcamr.v4i2.36353

ORIGINAL ARTICLE OPEN $\bigcirc$ ACCESS

\title{
Diagnostic Accuracy of Combined Use of MCV and MCH for the Detection of Thalassaemia Carrier
}

\author{
Nazmul Haque ${ }^{1}$, Sheikh Azimul Hoque ${ }^{2}$, Ariful Islam ${ }^{3}$, Yamin Shahriar Chowdhury ${ }^{4}$, \\ Bithi Debnath $^{5}$, Narayan Chandra Saha ${ }^{6}$
}

\begin{abstract}
${ }^{1}$ Assistant Professor, Department of Paediatric Neurology, National Institute of Neurosciences \& Hospital, Dhaka, Bangladesh; ${ }^{2}$ Associate Professor, Department of Paediatric Neurology, National Institute of Neurosciences \& Hospital, Dhaka, Bangladesh; ${ }^{3}$ Assistant Professor, Department of Paediatric Neurology, National Institute of Neurosciences \& Hospital, Dhaka, Bangladesh; ${ }^{4}$ Assistant Professor, Department of Paediatric Neurology, National Institute of Neurosciences \& Hospital, Dhaka, Bangladesh; ${ }^{5}$ Assistant Professor, Department of Paediatric Neurology, National Institute of Neurosciences \& Hospital, Dhaka, Bangladesh; ${ }^{6}$ Professor, Department of Paediatric Neurology, National Institute of Neurosciences \& Hospital, Dhaka, Bangladesh
\end{abstract}

[Reviewed: 30 February 2017; Accepted on: 1 April 2017; Published on: 1 July 2017]

\section{Abstract}

Background: Determination of thalassaemia carrier is the mainstay of prevention and in this context red cell indices like mean corpuscular volume $(\mathrm{MCV})$ and mean corpuscular haemoglobin $(\mathrm{MCH})$ provide valuable tool for determination thalassaemia carrier. Objective: The purpose of the present study was to determine the diagnostic test validity of combined use of MCV and $\mathrm{MCH}$ for the determination of thalassaemia carrier. Methodology: This case-control study was carried out in the Department of Pediatrics and Department of Medicine at MAG Osmani Medical College Hospital, Sylhet, Bangladesh from September 2007 to January 2009 for a period of one year and five months. Siblings and cousins of beta thalassaemia major and haemoglobin-E (Hb-E) beta thalassaemia at any age with both sexes were selected for this study. Detailed history and thorough physical examination were performed meticulously. MCV, $\mathrm{MCH}$ and $\mathrm{Hb}$-Electrophoresis were performed in all patients. Result: A total 128 siblings and cousins of beta thalassaemia major and $\mathrm{Hb}$ - E -beta thalassaemia were recruited for this study. Sensitivity, specificity, positive predictive value and negative predictive value of combine MCV \& $\mathrm{MCH}$ in determination of thalassaemia carriers are $95.2 \%, 93.8 \%, 93.7 \%$ and $95.3 \%$ respectively. Conclusion: In conclusion combined use of $\mathrm{MCV}$ and $\mathrm{MCH}$ has high diagnostic validity for the detection of thalassaemia carrier. [Journal of Current and Advance Medical Research 2017;4(2):40-43]

Keywords: Thalassaemia Carrier; mean corpuscular volume; mean corpuscular haemoglobin; diagnostic validity

Correspondence: Dr. Nazmul Haque, Assistant Professor, Department of Paediatric Neurology, National Institute of Neurosciences \& Hospital, Dhaka, Bangladesh; Email: nazmulk51@ gmail.com; Cell No.: +8801830008498

Cite this article as: Haque N, Hoque SA, Islam A, Chowdhury YS, Debnath B, Saha NC. Diagnostic Accuracy of Combined Use of MCV and MCH for the Detection of Thalassaemia Carrier. Journal of Current and Advance Medical Research 2017;4(2):40-43 Conflict of Interest: All the authors have declared that there was no conflict of interest.

Funding: This research project was not funded by any group or any institute on.

Contributions to authors: Haque $\mathrm{N}$ has involved in protocol preparation, data collection, data analysis and up to report writing; Hoque SA, Islam A, Chowdhury YS, Debnath B, Saha NC have written the manuscript and have revised the manuscript.

Copyright: (02017. Haque et al. Published by Journal of Current and Advance Medical Research. This article is published under the Creative Commons CC BY-NC License (https://creativecommons.org/licenses/by-nc/4.0/). This license permits use, distribution and reproduction in any medium, provided the original work is properly cited, and is not used for commercial purposes. 


\section{Introduction}

The thalassaemia is a heterogeneous collection of inherited disorders of hemoglobin synthesis which is characterized by a reduction in one or other of the globin chains that constitute adult hemoglobin ${ }^{1}$. Major component haemoglobins A ( $\mathrm{Hb} \mathrm{A}$ ) consists of a pair of alpha chains and a pair of beta chains. Therefore, there are two main classes of thalassaemia called $\alpha$ and $\beta$ thalassaemia which are resulting from defective $\alpha$ and $\beta$ chain synthesis respectively ${ }^{2}$.

Prevention of thalassaemia is the only solution of efficiently reduce the huge medical, social and economic impact of these disease in countries where these diseases occur in high frequencies ${ }^{3}$. Globally thalassaemia control has been achieved with public education, carrier screening, counseling, prenatal diagnosis and selective termination of affected fetuses ${ }^{4}$. The most successful preventive program have been developed appropriate to the needs of the community and sensitive to their cultural and social identity ${ }^{5}$. Public health concern about carrier detection and prenatal diagnosis of thalassaemia is not only confined to geographic areas with high disease prevalence but becomes a global issue due to population immigration ${ }^{6}$. Screening for thalassaemia in community based and antenatal programs for determination of red cell indices namely $\mathrm{MCV}$ and $\mathrm{MCH}$ are the initial $\mathrm{step}^{7}$. However, clinical guidelines and practices are variables. The British committee for standards in haematology recommends testing for beta thalassemia and alpha thalassemia traits when $\mathrm{MCH}$ is $<27 \mathrm{pg}$ and $<25 \mathrm{pg}$ respectively ${ }^{8}$.

In a study hemoglobin chromatography is performed for all subjects and further characterization of thalassaemia status is carried out for $\mathrm{MCV}<78 \mathrm{fl}$ and $\mathrm{MCH}<27 \mathrm{pg}^{9}$. Screening strategies based on MCV $<75 \mathrm{fl}$ and $\mathrm{MCV}<80 \mathrm{fl}$ have been described in Hongkong ${ }^{10}$; further investigation by $\mathrm{Hb}$ analysis or genotying are indicated for definitive diagnosis of thalassaemia carrier status in subjects with MCV or MCH below these cut of values.

When either MCV of MCH was considered for carrier status, sensitivity and specificity were less. Hence, selection of both MCV and MCH is ideally suited for further rapid confirmation of carrier status. This present study was undertaken to determine the diagnostic test validity of combined use of MCV and $\mathrm{MCH}$ for the determination of thalassaemia carrier.

\section{Methodology}

This present study was designed as analytical crosssectional study. This study was carried out in the Department of Pediatrics and Department of Medicine of Sylhet MAG Osmani Medical College Hospital, Sylhet, Bangladesh. This study was carried out from September 2007 to January 2009 for a period of one year and five months. The siblings and cousins of diagnosed cases of beta thalassaemia major and $\mathrm{Hb} \mathrm{E}$ beta thalassaemia with the age group of 1 to 20 yrs who were presented with the $\mathrm{HbA}_{2}$ level more than $3.5 \%$ were selected as case group and those who were presented with $\mathrm{HbA}_{2}$ less than $3.5 \%$ were selected as control group. Iron deficiency anemia diagnosed clinically by moderate to severe pallor, angular stomatitis, smooth tongue, koilonychias, hepatomegaly and subjects below 1 year were excluded from this study. Both case and control groups were selected by systematic random sampling by choosing every $2^{\text {nd }}$ case. Siblings aging more than 1 year, first degree cousins of the patient diagnosed as beta thalassemia, E-beta thalassaemia by $\mathrm{Hb}$-Electrophoresis were interviewed and detailed history was taken and thorough physical examination were done; $5 \mathrm{ml}$ blood was taken for $\mathrm{MCV}, \mathrm{MCH}, \mathrm{Hb}$ electrophoresis. Two (2) $\mathrm{mL}$ was introduced into automated cell counter in haematology laboratory of private diagnostic centre in Sylhet (Medinova Medical Service Ltd., Sylhet and Popular Diagnostic Center Ltd., Sylhet) for MCV \& $\mathrm{MCH}$ and three (3) $\mathrm{mL}$ anti-coagulated blood was sent to Dhaka in two private diagnostic laboratories (Medinova Medical Service Ltd., Dhanmondi, Dhaka and Popular Diagnostic Center Ltd., Dhanmondi, Dhaka) by air incubated in freeze for $\mathrm{Hb}$ electrophoresis. MCV and MCH test was carried out by SYSMEX XT1800i cell counter. Hemoglobin electrophoresis is carried out by Serbia Automated System on agarose gel (Hydragel). Controls were also investigated for $\mathrm{MCV}, \mathrm{MCH}$ and $\mathrm{Hb}$-Electrophoresis. Sensitivity, Specificity, positive and negative predictive values were calculated. Data were collected by a structured questionnaire were analyzed and interpreted duly using computer software SPSS 20.0. Informed written consent was taken before data collection. Permission from the local Ethical committee of SMAGMOC was taken.

\section{Result}

A total number of 128 respondents were recruited for this study of which 63 respondents were in case 
group and 65 respondents were in control group. Among 63 respondents in case group combined use of $\mathrm{MCV}$ and $\mathrm{MCH}$ were positive in 60(95.2\%) cases and negative in $3(4.8 \%)$ cases. Again, out of 65 respondents in control group combined MCV and $\mathrm{MCH}$ was positive in 4(6.2\%) respondents and negative in $61(93.8 \%)$ respondents. The association between these two groups was statistically significant $(\mathrm{p}=0.0001)($ Table 1$)$.

Table 1: Association of Combined Use of MCV and $\mathrm{MCH}$ in Determination of Thalassemic Carrier

\begin{tabular}{|c|c|c|c|}
\hline $\begin{array}{l}\text { Combined } \\
\text { MCV \& } \\
\text { MCH }\end{array}$ & Cases & Controls & Total \\
\hline Positive & $60(95.2 \%)$ & $4(6.2 \%)$ & $64(50.0 \%)$ \\
\hline Negative & $3(4.8 \%)$ & $61(93.8 \%)$ & $64(50.0 \%)$ \\
\hline Total & $63(100.0 \%)$ & $65(100.0 \%)$ & $128(100.0 \%)$ \\
\hline
\end{tabular}

Sensitivity and Specificity of combine MCV \& $\mathrm{MCH}$ in the diagnosis of thalassemic carriers were found $95.2 \%$ and $93.8 \%$ respectively \& were very high. The Positive predictive value and Negative predictive value of $\mathrm{MCV}+\mathrm{MCH}$ in the diagnosis of thalassemic carriers were found $93.7 \%$ and $95.3 \%$ respectively (Table 2 ).

Table 2: Validity of Combined Use of MCV and MCH in Determination of Thalassemic Carrier

\begin{tabular}{l|l|l|}
\hline Validity & Value & 95\% CI \\
\hline Sensitivity & $95.2 \%$ & $86.71 \%$ to $99.01 \%$ \\
\hline Specificity & $93.8 \%$ & $84.99 \%$ to $98.30 \%$ \\
\hline PPV & $93.7 \%$ & $85.28 \%$ to $97.49 \%$ \\
\hline NPV & $95.3 \%$ & $87.06 \%$ to $98.40 \%$ \\
\hline Accuracy & $94.5 \%$ & $90.55 \%$ to $98.45 \%$ \\
\hline
\end{tabular} $\begin{aligned} & \text { PPV=Positive Predictive Value; NPV=Negative Predictive } \\
& \text { Value }\end{aligned}$

\section{Discussion}

Difficulties in screening for the thalassemic carrier are related to the heterogeneity of Beta thalassemia and the absence of a single test to cover all Bthalassemia variants. The most accurate tests for the detection of thalassemic carriers are genetic detection and globin chain determination, both of which are either very expensive or not available for screening programs in third world countries like Bangladesh $^{10}$.

Selection of both MCV $(<77 \mathrm{fl})$ and $\mathrm{MCH}(<27 \mathrm{Pg})$ is ideally suited for further rapid confirmation of carrier status ${ }^{9}$. The present study found that when $\mathrm{MCV} \& \mathrm{MCH}$ if considered combined, the sensitivity, specificity, positive predictive value, negative predictive value is higher.

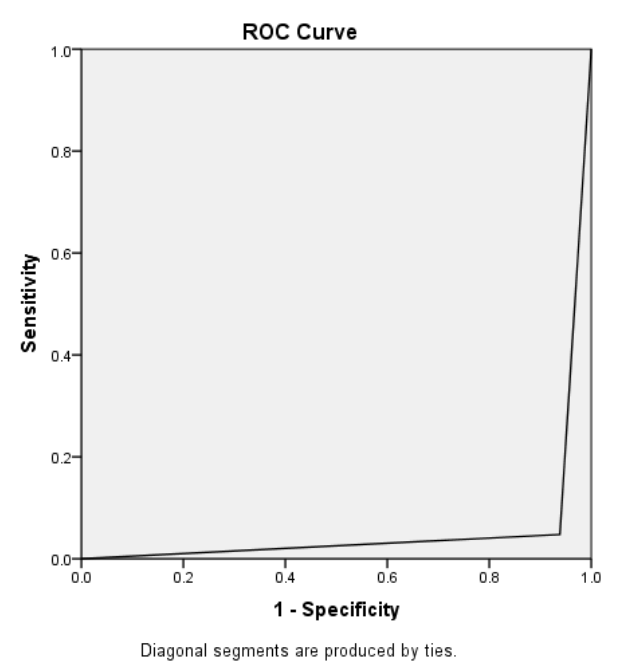

Figure I: The ROC curve for combined use of MCV and MCH value for Detection of Thalassaemia Carriers

Causes of decreased $\mathrm{MCV}$ and $\mathrm{MCH}$ can result from a defect in globin genes, in heme synthesis, in iron availability or in iron acquisition by the erythroid precursors. These microcytic anemia can be a trait which reflects the implications of different gene abnormality ${ }^{11}$. Degree of reduction of MCV and $\mathrm{MCH}$ in iron deficiency tends to parallel the severity of the anemia which contrasts with most cases of heterogygous thalassemia in which the $\mathrm{MCV}$ and $\mathrm{MCH}$ are disproportionately low ${ }^{12}$.

Table 3: Value of Area Under the Curve of MCV value for Detection of Thalassaemia Carriers

\begin{tabular}{|c|c|c|c|}
\hline \multirow[t]{2}{*}{ Area } & \multirow[t]{2}{*}{ P value } & \multicolumn{2}{|c|}{$\begin{array}{l}\text { Asymptotic } 95 \% \\
\text { Confidence Interval }\end{array}$} \\
\hline & & $\begin{array}{l}\text { Lower } \\
\text { Bound }\end{array}$ & $\begin{array}{l}\text { Upper } \\
\text { Bound }\end{array}$ \\
\hline 0.055 & 0.0001 & 0.009 & 0.100 \\
\hline
\end{tabular}

The test result variable(s): MCH_MCV has at least one tie between the positive actual state group and the negative actual state group. Statistics may be biased; a. Under the nonparametric assumption; $b$. Null hypothesis: true area $=0.5$

However, it may be recalled that another method of carrier detection is NESTROFT (Naked eye single tube red cell osmotic fragility test). In a current study in India on 1048 antenatal women sensitivity, specificity, positive and negative predicative values of NESTROFT were $91.0 \%$, $95.0 \%, 55.0 \%, 99 \%$ respectively ${ }^{9}$. The result of 
this study has similar result with the current study. A hospital based descriptive study using same population of this current study by another author in Sylhet. Where sensitivity, specificity, positive and negative predictive values of NESTROFT were $94.3 \%, 88.6 \%, 89.1 \% \& 94 \%$ these findings are in conformity with the result current study ${ }^{13}$.

All the study including current study have lower positive productivity suggested false positive results probably due to associated iron deficiency which requires confirmation by estimation of $\mathrm{Hb}$ A2 levels ${ }^{14}$. Based on high negative predictive values, the used of combined $\mathrm{MCV}$ and $\mathrm{MCH}$ has been recommended for mass screening. Sensitivity, specificity and predictive values of MCV are high in determination of Thalassemic carrier, when results of $\mathrm{MCV}$ and $\mathrm{MCH}$ are combined the validity are higher. Combined MCV and $\mathrm{MCH}$ can be used as mass screening for detection of Thalassemic carrier.

Further multi-centered, population based, large sized, well financed and lab facilitated study may provide more valid result. Information generated in this present study may be potentially useful in making decisions regarding nationwide mass screening programme, prevent Thalassemia and building thalassemia free healthy Bangladesh. Iron deficiency anemia can't be excluded by laboratory test by RDW due to more financial burden on the study. Sample size was small. The study includes cousins and siblings of both beta thalassemia major and Hb-E-beta thalassemia. Hb-E electrophoresis facility is not available in Sylhet, available only in Dhaka city of Bangladesh.

\section{Conclusion}

In conclusion sensitivity, specificity and predictive values of each of MCV and MCH are high in detection of thalassemic carriers (beta thalassemia major and $\mathrm{Hb}-\mathrm{E}$ beta thalassemia) in the age range of 1 year to 20 years. When results of MCV and $\mathrm{MCH}$ are combined, the sensitivity, specificity and predictive values are higher. Combined MCV \&
$\mathrm{MCH}$ can be employed for detection of thalassemic carriers of beta thalassemic major $\mathrm{Hb}$ E beta thalassemic.

\section{Reference}

1. Weatherall DJ, Clegg JB, Higgs DR, Wood WG, Scriver $\mathrm{CR}$, Beaudet A, et al. The metabolic and molecular basis of inherited disease. New York: MC Graw Hill; 2001: 4592.

2. Wethers D, Pearson H, Gaston M. Newborn screening for sickle cell diseases and other hemoglobiriopathies. Paediatrics 1999;83:813-4.

3. Fairbanks V. Hemoglobinopathies and thalassemia, laboratory methods and clinical cases. New York: Thieme-stration inc., 1990:18.

4. Goljan E. Pathology, $2^{\text {nd }}$ ed, Mosby Elsevier, Rapid Review Series. New York, 2002;298-299.

5. Model B, Update of Epidemiology of hemoglobin disorders with special references to thalassemia, thalassemia international federation. 2003;16:122-127

6. WHO guidelines for control of hemoglobin disorders, Unpublished Document WHO/HDP/HB/GI/94. Obtainable free of charge from the hereditary Disease programme,WHO,Geneva, Switzerland.2001;79:8

7. Manjula M, Sadhna A, Madhulika K, Menon P.S.N. Carrier screening and prenatal diagnosis of bata thalassemia. Indian pediatrics 1999; 36:1119-1125.

8. Cao A, Rosatelli C. Screening and prenatal diagnosis of the hemoglobinopathies, Bailliere's clin haematol.1993; 6:263-86.

9. Tosun F, Bilgin A, Kizilok A, Arpaci A, Yuregir G.T. Premarital screening program in Mersin, Turkey. Turk $\mathbf{J}$ Hematology 2006; 23 (2): 2006 (84-89).

10. Weatherall DJ, Letsky EA. Genetic haematological disorder. Antenatal and neonatal screening. Oxford. Oxford University Press. 2000: P-243.

11. Sin SY. Gnosh A, Tang LC, Chan V. Ten year's experience of antenatal mean corpusculuar volume screening and prenatal diagnosis for thalassemia in HongKong. J. Obstet Gynaecol Res 2000; 26:203-8

12. Lau YL, Chan LC, Chan YY. Prevalence and genotypes of beta thalassemia carriers in Hong Knog, implication for population screening. N. Engl. J Med. 1997; 336:1298-301.

13. Chan LC, Ma SK, Chan A. Should we screen for globin gene nedian in blood samples with mean corpuscular volume $(\mathrm{MCV})$ greater than $80 \mathrm{ft}$ in areas with a higher prevalence of thalassemia. J. Clin pathol 2001; 54:31720.

14. Shine I, Lal S. A strategy to detect beta thalassemia minor. Lancet 1997; 1:692-694 